\title{
A Survey of Kansas Physicians’ Perceptions of Physician Assistant Education and Qualifications
}

Gina R. Brown, M.P.A.S., PA-C, LaDonna S. Hale, Pharm.D., Molly C. Britz, M.P.A., PA-C, Mindy J. Schrader, M.P.A., PA-C, Sedera L. Sholtz, M.P.A., PA-C, Madalyn J. Unruh, M.P.A., PA-C

Wichita State University College of Health Professions

Department of Physician Assistant

\begin{abstract}
Background. Effective physician-physician assistant (PA) teams improve patient access and satisfaction, and increase productivity and revenue while reducing physician workload. This survey assessed perceptions of Kansas primary care physicians regarding educational requirements and qualifications of PAs, professional and legal regulations, and the most important skills and competencies for PAs to possess. Understanding these perceptions may lead to improved communication and refined expectations of physician-physician assistant teams, thereby increasing their utilization and effectiveness.

Methods. A 20-question survey was emailed to all 1,551 primary care physicians registered with the Kansas Board of Healing Arts in 2012. Descriptive data were reported as frequencies; comparisons between groups were analyzed using Chi-square.

Results. The response rate was $9.2 \%(n=143)$. Physicians were highly accurate regarding the program's generalist/primary care educational model and moderately accurate regarding the degree awarded, average pre-program grade point average, lock-step full-time curriculum, weeks of clinical rotations, recertification and continuing medical education hours, and Medicare PA fee schedule. Physicians had low accuracy regarding program and pharmacology credit hours, strict dismissal policy, pre-program healthcare experience, and co-signatory regulations. Physicians with PA supervisory experience had higher knowledge than those without $(\mathrm{p}=$ 0.001). Physicians most commonly selected history taking and performing physical exam as the most important skill (49\%) and providing patient care that is patient-centered, efficient, and equitable as the most important competency (42\%).

Conclusions. Physicians often underestimated the average PA applicant qualifications, program rigor and intensity, professional regulatory standards, and co-signatory requirements. Correcting misperceptions and improving understanding of which PA skills and competencies are most valued by physicians may optimize PAs as part of the healthcare team.
\end{abstract}

KS J Med 2015; 8(1):18-25.

\section{Introduction}

The increasing demand for primary care providers continues to steer the healthcare system toward a shared role between physicians and midlevel providers. The demand is rising largely due to population growth, the Affordable Care Act, and the aging population. ${ }^{1}$ In addition to an increase in the number of insured patients, health plans are required now to cover certain preventive services without cost sharing to the patient, resulting in an increased demand for primary care providers. ${ }^{2}$ Physician assistants (PAs) can meet this increasing need; however, it seems reasonable to assume that incorrect perception of their education, qualifications, and economic benefits may hinder their full utilization. Currently, over 180 accredited programs 
exist in the United States and the number of practicing PAs has doubled in the last decade. ${ }^{3,4}$

PAs practice medicine with delegated autonomy as part of a healthcare team with the supervision of a licensed physician. The level of autonomy is delegated by the supervising physician as appropriate, and depends upon the PA's training, experience, and scope of practice. PAs are able to make healthcare decisions and carry out responsibilities without the need for input on these decisions unless the PA determines that physician input is necessary. It is much like the relationship between a physician and resident. $^{5}$ In a primary care setting, the services that a PA can provide are close to $90 \%$ of what the physician provides. $^{6}$ Effective physician-PA teams improve patient access and patient satisfaction, 7,8 enhance day-to-day coordination of care and cost-effectiveness, ${ }^{9,10}$ and increase productivity and revenue while reducing physician workload. ${ }^{5,11}$

Like many areas of the nation, most rural and some urban areas of Kansas are designated as underserved due to a shortage of primary care providers. Expanding medical schools partially will alleviate these shortages. Increased utilization of midlevel providers is also important to meet the nation's growing healthcare needs. PA education strives to develop PAs that will have a shared role, along with the physician, in providing quality care to patients. If physicians understand what is included in a PAs education, this shared role may be optimized.

The Wichita State University (WSU) PA program has been the only PA program in the state of Kansas since 1972. It is similar to other programs across the nation in length, structure, rigor, applicant qualifications, and degree awarded. ${ }^{3}$ The program's longevity, plus the fact that students learn from over 100 preceptors scattered through-out the state, would lead to an expectation of familiarity and knowledge among the Kansas medical community of what competencies a PA can offer a patient-centered medical team. However, since many physicians have limited experience in working on a team with a PA, this expectation may not prove true. If physicians do not realize, for example, that PAs complete six graduate hours of pharmacology and are licensed to prescribe medications, this misperception could serve as a barrier and hinder their functionality as a team.

The purpose of this survey was to assess the perceptions of Kansas primary care physicians regarding the educational requirements and qualifications of PAs, post-graduate professional and legal regulations, and the most important skills and competencies for PAs to possess. Understanding these perceptions may remove barriers to the optimization of PAs as part of the healthcare team, and in turn help to meet the increased demand for primary care providers.

\section{Methods}

A cross-sectional survey was emailed to 1,551 primary care physicians registered with the Kansas Board of Healing Arts. Primary care physicians were defined as family practice, pediatric, and internal medicine physicians. The survey was open from May 2012 through July 2012. Nonresponders were emailed two additional times.

The 20-question, non-validated survey consisted of five demographic questions and nine knowledge assessment questions pertaining to WSU's qualifications of accepted applicants, degree awarded, program credit hours, pharmacology credit hours, program structure, educational model, and required clinical hours. Four questions asked about PA recertification, continuing 
medical education (CME) requirements, and legal aspects of PA supervision. Two questions assessed beliefs regarding essential skills and competencies for a PA to possess.

Data analysis and IRB approval. Surveys with less than $50 \%$ of the questions completed were excluded from analysis. Data were analyzed using SPSS 19.0 (Chicago, IL). Descriptive data were reported as frequencies. For ease of discussion throughout the paper, level of knowledge is categorized as either high, moderate, or low accuracy. Questions for which the frequency of correct responses was greater than $75 \%$ were classified as "high accuracy", 40-75\% as "moderate accuracy", and less than $40 \%$ as "low accuracy". Physicians would not be expected to be intimately familiar with every aspect of PA education or certification/legal aspects, thus the categories were defined somewhat arbitrarily using the natural data cut-off points and an assumption that "high accuracy" should be set at what would be considered an acceptable score on an academic or CME test.

Comparisons between groups were analyzed using Pearson's Chi-square with statistical significance set at $\mathrm{p}<0.05$. The study was approved by the WSU Institution Review Board and completion of the survey indicated consent.

\section{Results}

Of the 170 responses, 27 were incomplete resulting in a response rate of $9.2 \%(143 / 1,551)$. Of those, $67 \%$ were male, $79 \%$ had been practicing for over 10 years, and $58 \%$ were 50 -years-old or older. Rural (population < 100,000) versus urban (population $\geq 100,000$ ) demographics were $49 \%$ vs. 51\%, respectively, and 65\% stated they had supervised a PA.

Perceptions regarding the WSU PA program and typical program students.
Physicians identified only one aspect of the WSU PA Program with high accuracy, the generalist/primary care medical model of education (84\%). Four aspects were identified with moderate accuracy: the Master degree designation (64\%), the average pre-program GPA (56\%), the program's lock-step full-time curriculum (all students begin and end together; 51\%), and the number of weeks of clinical rotations (49\%). Four aspects were identified with low accuracy: number of program graduate credit hours (30\%), number of pharmacology credit hours (26\%), the program's policy that failed courses result in program dismissal (21\%), and the average number of pre-program direct patient care experience hours (19\%; Table 1).

Perceptions regarding post-graduate PA requirements. None of the questions were answered with high accuracy. Three aspects were identified with moderate accuracy: frequency of required recertification (60\%), number of required CME hours annually (50\%), and the Medicare PA fee schedule (43\%). Only $37 \%$ were aware that supervising physicians in Kansas are no longer required to co-sign all patient encounter notes written by PAs (Table 2).

Comparisons between groups of physicians. There was no statistical difference between the mean knowledge score of rural versus urban physicians or between physicians under or over 50-yearsold. As expected, physicians who had supervised a PA had a higher mean knowledge score than physicians who had not supervised a PA ( $p=0.001)$. Physicians who had supervised a PA were more likely to identify correctly the educational model as generalist/primary care medical school model (91\% vs 79\%, p = 0.001), the lockstep full-time curriculum (60\% vs 35\%, p = 0.006), and the required annual CME hours (56\% vs $37 \%$, $p=0.034$ ). 
Table 1. Physicians’ perceptions regarding current education of WSU PA students.

\begin{tabular}{|c|c|}
\hline What degree is awarded to graduates of the WSU PA program? & $\%(n)$ \\
\hline Bachelor & $34 \%(47)$ \\
\hline Master* & $64 \%(88)$ \\
\hline Doctorate & $2 \%(2)$ \\
\hline \multicolumn{2}{|c|}{ What is the total number of graduate credit hours obtained during the PA program? } \\
\hline$\leq 60$ hours & $40 \%(53)$ \\
\hline 61-80 hours & $30 \%(40)$ \\
\hline$>80$ hours $*$ & $30 \%(39)$ \\
\hline \multicolumn{2}{|c|}{$\begin{array}{l}\text { What is the number of graduate credit hours in pharmacology that PA students must complete } \\
\text { in order to graduate from the WSU PA program? }\end{array}$} \\
\hline $2-4$ hours & $25 \%(33)$ \\
\hline 6 hours* & $26 \%(34)$ \\
\hline 8 hours & $50 \%(65)$ \\
\hline \multicolumn{2}{|c|}{$\begin{array}{l}\text { Which of the following do you think best describes the education model of the WSU PA } \\
\text { program? }\end{array}$} \\
\hline Generalist/primary care medical model* & $84 \%(111)$ \\
\hline Generalist/primary care nursing model & $8 \%(10)$ \\
\hline Specialty oriented & $9 \%(12)$ \\
\hline \multicolumn{2}{|l|}{ Which statement regarding the structure of the PA curriculum is true? } \\
\hline Lock-step, full-time curriculum* & $51 \%(67)$ \\
\hline Options for part-time or full-time & $49 \%(64)$ \\
\hline \multicolumn{2}{|l|}{ Which statement regarding the structure of the PA curriculum is true? } \\
\hline Failed courses may be repeated & $80 \%(104)$ \\
\hline Failed courses result in program dismissal* & $21 \%(27)$ \\
\hline \multicolumn{2}{|c|}{$\begin{array}{l}\text { What is the total number of weeks of direct clinical experience PA students must complete } \\
\text { while in the program? }\end{array}$} \\
\hline$\leq 30$ weeks & $32 \%(42)$ \\
\hline 31-40 weeks & $20 \%(26)$ \\
\hline$>40$ weeks* & $49 \%(65)$ \\
\hline
\end{tabular}

*Indicates correct answer. Note: Percentages may not equal 100 due to rounding.

Perceptions regarding important skills and competencies for PAs. Figures 1 and 2 show what physicians selected as the most important skill and competency for PAs. Forty-nine percent selected history taking and performing physical exam as the most important skill for PAs. Patient care that is patient centered, efficient, and equitable was the leading competency selected (42\%).

\section{Discussion}

Studies from other states ${ }^{12,13}$ have shown mixed perceptions of physicians which include an uncertainty as to the level of care a PA can provide, such as whether a PA can take call or round at the hospital. Other uncertainties involved how a physician's workload might be affected if they took on the supervisory responsibility of a PA. These uncertainties seemed to stem from perceptions of state regulations as well as training of PAs. One study suggested that programs provide education to physicians on appropriate roles for PAs to maximize the effectiveness of both providers. ${ }^{13}$ The authors stated that "If the use of 
Table 2. Physicians’ perceptions regarding PA post-graduate requirements.

\begin{tabular}{l|c}
\hline How many CME hours are required annually of Physician Assistants? & $\mathbf{\% ~ ( n ) ~}$ \\
\hline 30 CME hours & $34 \%(45)$ \\
\hline 40 CME hours & $17 \%(22)$ \\
\hline 50 CME hours* & $50 \%(66)$ \\
\hline How often are PAs required to re-take national certifying examinations? \\
\hline Never & $12 \%(16)$ \\
\hline Every 3 years & $15 \%(20)$ \\
\hline Every 6 years*† & $60 \%(81)$ \\
\hline Every 9 years & $13 \%(17)$ \\
\hline $\begin{array}{l}\text { Is it a legal requirement for supervising physicians in Kansas to co-sign all patient-encounter } \\
\text { notes written by PAs? }\end{array}$ & $53 \%(73)$ \\
\hline Yes & $37 \%(51)$ \\
\hline No* & $11 \%(15)$ \\
\hline Unsure
\end{tabular}

*Indicates correct answer. $\uparrow$ National certifying examinations taken for re-certification began new requirements and schedule in 2014. PAs will transition to a new 10-year cycle over the next five years. Note: Percentages may not equal 100 due to rounding.

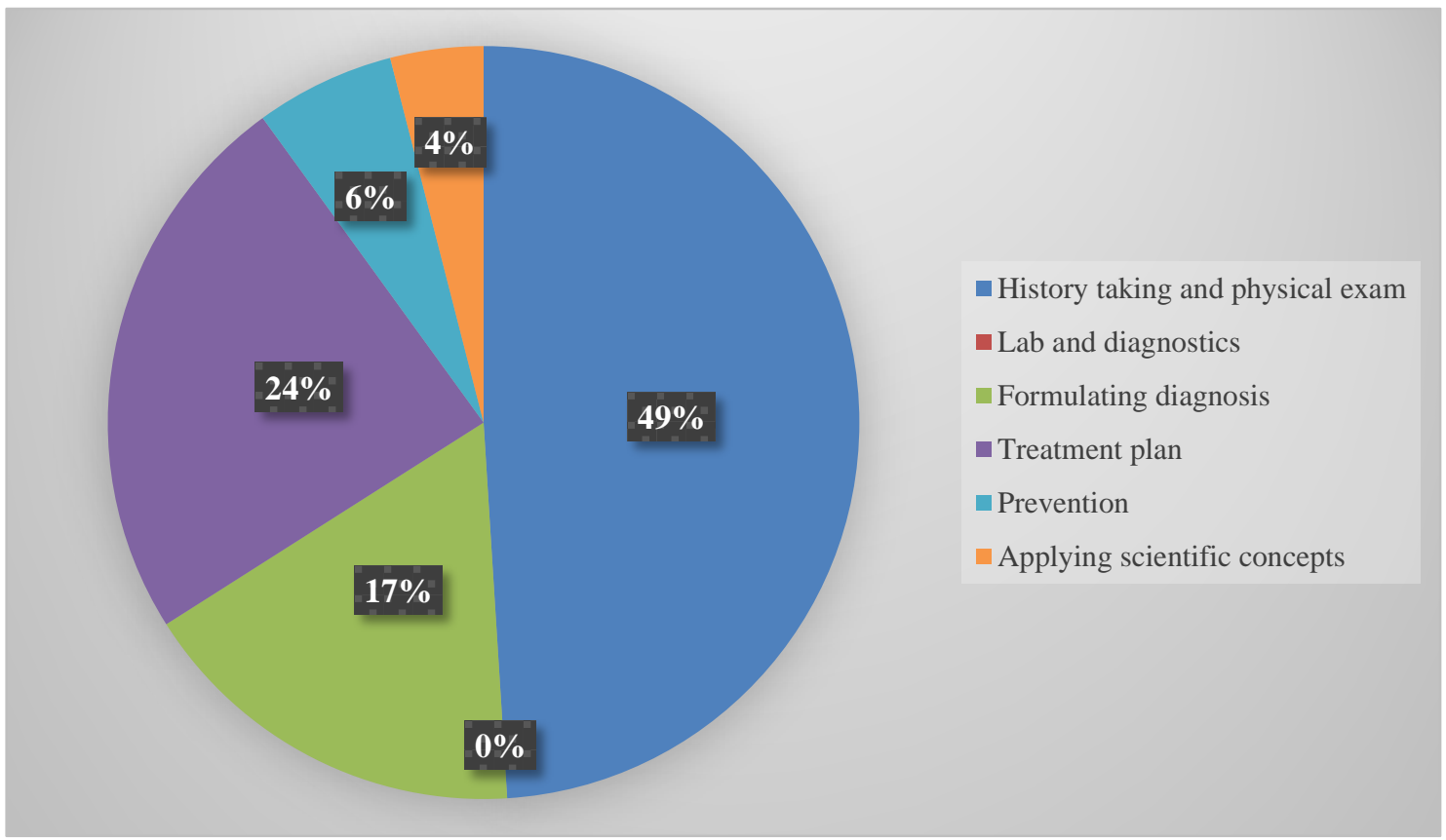

Figure 1. What do you as a physician believe is the most important skill for a PA?

non-physician providers is to be optimized $\ldots$ awareness and acceptance of their capabilities by rural family physicians is essential."13 This survey evaluated perceptions of Kansas physicians regarding Kansas physician assistants and identified some misperceptions. The intent of this article was to provide some clarification regarding these misperceptions, which should allow a physician-PA team to work more freely within their appropriate boundaries. 


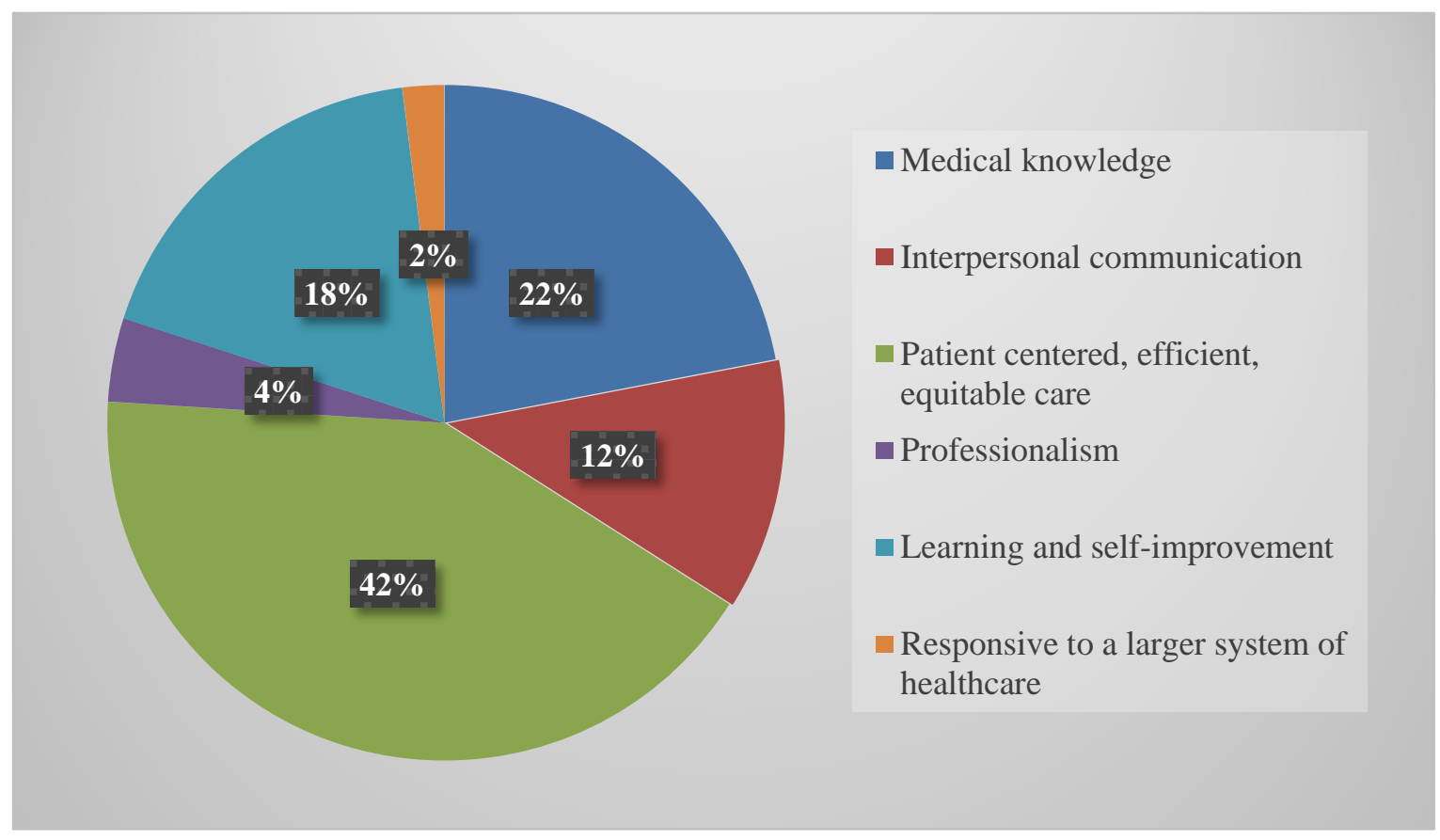

Figure 2. What do you as a physician believe is the most important competency for a PA?

Kansas physicians tended to underestimate the average PA applicant qualifications and program rigor and intensity. A better understanding of the intellectual potential, economic value, and patient care experience that a PA, even a new graduate, can bring to the healthcare team may increase their utilization. Although direct patient care experience is not a requirement for acceptance into the WSU program, it is strongly recommended.

Physicians tended to underestimate the fact that accepted applicants have completed an average of over 2,000 hours of direct patient care. Only $30 \%$ of respondents knew that over 80 graduate credit hours (currently 83 hours) are necessary to complete the WSU program. Physicians also tended to be unfamiliar with other aspects of the program's rigor and high academic expectations including its lock-step, fulltime nature, that a single failed course results in program dismissal, and that in most units of study, unacceptable academic/ clinical performance is defined as less than
$72 \%$. After graduation, PAs are held to high professional regulatory standards regarding mandatory national recertification every 10 years and 50 CME hours annually, often exceeding post-graduate requirements of other allied healthcare professionals and midlevel providers.

The only question to which physicians overestimated the rigor of the program was related to the number of hours of pharmacology. The WSU PA program requires six credit hours of pharmacology which was answered correctly by $26 \%$ of physicians, yet $49 \%$ believed the program required eight hours of pharmacology. The national average for PA programs is around five credit hours. ${ }^{14}$

Kansas regulations state that, during the first 90 days of employment, supervising physicians are required to review and authenticate all medical records of patients cared for by the PA. This requirement allows the physician time to assess the PA's skills and competency adequately within the practice setting and develop an informed 
decision regarding the appropriate level of delegated autonomy within which the PA will practice. After the first 90 days, supervising physicians are required to complete a periodic review and evaluation of the PA's performance. ${ }^{15}$ Over $63 \%$ of physicians were unaware of these legal requirements regarding co-signatures. Even though physicians with experience supervising PAs had higher overall knowledge scores than physicians who had not, there was no statistically significant difference between the groups regarding their understanding of this regulation. The incorrect assumption that all medical notes documented by a PA must be co-signed by a physician could make some physicians hesitant to form a physician-PA team.

Understanding what is valued most by physicians can help PAs form more effective teams with their supervising physicians. In this set of questions, respondents were allowed to select the one skill and one competency they felt was most important. The six skills on the survey were the six categories of questions found on the PA national certifying exams. For PA educators, understanding that history taking and performing physical exams ranked highest as the most important skill for a PA to possess, can lead to an appropriate emphasis of this skill in the WSU curriculum, allowing students to be well prepared for their role in the health-care team.

The six competencies on the survey were the same six areas in which students are evaluated by their clinical preceptors during the second year of the WSU PA program. The most important competency was efficient, equitable, patient-centered care, with few respondents choosing professionalism or a responsiveness to the larger health-care system. Again, this understanding can guide PA educators in their efforts to prepare students for team-based care and enhanced coordination between the physician and the PA.

Study limitations. Due to the low response rate, survey results must be interpreted with caution. The survey only evaluated primary care physicians and cannot be generalized to physicians in specialty practices. Although most questions regarding the WSU PA Program are reflective of PA programs across the nation, several were specific to the WSU PA Program, therefore, may not be generalizable to other programs. It is, however, a first step in evaluating the perceptions of Kansas physicians regarding PA education and qualifications, postgraduate professional and legal regulations, and important skills and competencies for PAs to possess.

\section{Conclusions}

Kansas physicians often underestimated the average PA applicant qualifications, program rigor and intensity, and postgraduate professional regulatory standards. Responses also indicated a misunderstanding of new co-signatory requirements. This underestimation may cause the physician to limit the care a PA can provide in prescribing medications unnecessarily, for example, taking call or rounding in the hospital. The misunderstanding of co-signatory requirements may cause physicians to feel unnecessarily burdened by their supervisory role.

Correcting misperceptions may optimize PAs as part of the healthcare team and help to meet the increased demand for primary care providers. The findings from this survey will be utilized by the WSU Physician Assistant Program to educate their students, their physician contacts, and health care administrators as to how PAs can be utilized appropriately to maximize the 
effectiveness of a health care team and

\section{References}

${ }^{1}$ Petterson SM, Liaw WR, Phillips RL Jr, Rabin DL, Meyers DS, Bazemore AW. Projecting US primary care physician workforce needs: 2010-2025. Ann Fam Med 2012; 10(6):503-509. PMID: 23149526.

2 Day J. Affordable care act (ACA) summary and updates. World Institute on Disability 2010. Available at: http://wid.org/news/affordable-care-act-ac a-summary-and-updates. Accessed April 9, 2014.

3 Physician Assistant Education Association. PA Programs Directory. Available at: http://directory.paeaonline.org/. Accessed June 22, 2014.

${ }^{4}$ Sutton JP, Ramos C, Lucado J. US physician assistant (PA) supply by state and county in 2009. J Am Acad Physician Assist 2010; 23(9):5-8.

5 American Academy of Family Physicians, American Academy of Physician Assistants. Family physicians and physician assistants: Team-based family medicine: Joint policy statement. February 16, 2011. Available at: http://www.aafp. org/about/policies/all/fp-pa.html. Accessed June 11, 2014.

${ }^{6}$ Hooker RS. Physician assistants and nurse practitioners: The United States experience. Med J Aust 2006; 185(1):4-7. PMID: 16813537.

${ }^{7}$ Hooker RS, Cipher DJ, Sekscenski E. Patient satisfaction with physician assistant, nurse practitioner, and physician care: A national survey of Medicare beneficiaries. J Clin Outcomes Manag 2005; 12(2):88-92.

8 Roblin DW, Becker ER, Adams EK, Howard DH, Roberts MH. Patient satisfaction with primary care: Does type provide quality patient outcomes.

of practitioner matter? Med Care 2004; 42(6):579-590. PMID: 15167326.

${ }^{9}$ Ackerman RJ, Kemle KA. The effect of a physician assistant on the hospitalization of nursing home residents. J Am Geriatr Soc 1998; 46(5):610-614. PMID: 9588375.

${ }^{10}$ Ouslander JG, Lamb G, Perloe M, et al. Potentially avoidable hospitalizations of nursing home residents: Frequency, causes, and costs. J Am Geriatr Soc 2010; 58(4):627-635. PMID: 20398146.

${ }^{11}$ Roblin DW, Howard DH, Becker ER, Kathleen Adams E, Roberts MH. Use of midlevel practitioners to achieve labor cost savings in the primary care practice of an MCO. Health Serv Res 2004; 39(3):607626. PMID: 15149481.

${ }^{12}$ Burgess SE, Pruitt RH, Maybee P, Metz AE Jr, Leuner J. Rural and urban physicians' perceptions regarding the role and practice of the nurse practitioner, physician assistant, and certified nurse midwife. J Rural Health 2003; 19(5):321328. PMID: 14526515.

${ }^{13}$ Bergeson J, Cash R, Boulger J, Bergeron D. The attitudes of rural Minnesota family physicians toward nurse practitioners and physician assistants. J Rural Health 1997; 13(3):196-205. PMID: 10174610.

${ }^{14}$ Association of Physician Assistant Programs. Nineteenth annual report on physician assistant educational programs in the United States, 2002-2003. Alexandria, VA: Physician Assistant Education Association, 2003.

${ }^{15}$ Kansas Board of Healing Arts. Article 28a. Physician Assistants. Available at: http://www.ksbha.org/regulations/article28 a.shtml. Accessed September 21, 2012.

Keywords: physician assistants, education, primary care access, primary care health, primary care physicians, Kansas 